\title{
A Study of Durations for Korean Vowels at Isolated Utterance Condition
}

\author{
Kyungju Lee ${ }^{1}$, In-Ki Jin² \\ 'Department of Speech Pathology and Audiology, Graduate School, Hallym University, Chuncheon, Korea \\ ${ }^{2}$ Division of Speech Pathology and Audiology, Research Institute of Audiology and Speech Pathology, College of Natural Sciences, Hallym University, \\ Chuncheon, Korea
}

\section{독립발화조건에 따른 한국어 모음 길이 연구}

이 경 주 ${ }^{1}$ 진 인 기

한림대학교 일반대학원 언어병리청각학과 ${ }^{1}$, 한림대학교 자연과학대학 언어청각학부, 청각언어연구소 ${ }^{2}$

\begin{abstract}
Purpose: The purpose of this study was to measure durations of Korean vowels. Methods: Using a speech-recording program, 20 normal-hearing participants recorded 20 Korean vowels. Each vowel was recorded five times and the second, third, and fourth recorded vowel durations were used for analysis of durations. Results: On average, vowel durations for female speakers were longer than the durations for male speakers. Specifically, 11 vowel durations for female speakers were significantly longer than the durations for male speakers and the other nine vowel durations for female speakers were not. In addition, across-vowel differences in duration were evident not only for male speakers but also for female speakers. Generally, durations of diphthongs were longer than durations of monophthongs. Conclusion: The results of this study provide information about effects of gender and vowels in vowel durations. Vowel durations may be one factor to discriminate vowels.
\end{abstract}

Key Words: Acoustic characteristics, Vowel, Duration.

Received: June 17, 2016 / Revised: June 28, 2016 / Accepted: July 1, 2016

Correspondence: In-Ki Jin, Division of Speech Pathology and Audiology, Research Institute of Audiology and Speech Pathology, College of Natural Sciences, Hallym University, 1 Hallimdaehak-gil, Chuncheon 24252, Korea

Tel: +82-33-248-2221 / Fax: +82-33-256-3420 / E-mail: inkijin@hallym.ac.kr

\section{INTRODUCTION}

우리나라의 언어에서 모음(vowel)은 음성학적 관점에서 매 우 중요한 역할을 한다. 모음은 성문(glottis)의 특정 위치에서 성도를 열어 조음기관의 방해 없이 스스로 소리를 낼 수 있어 '홀소리'라고 정의되기도 한다(National Institute of Korean Language, 2016). 이렇게 모음은 음절을 이루기 위해 반드시 하나 이상의 모음과 결합해야 하는 자음(consonant)과 달리 하나의 모음만으로도 소리를 낼 수 있는 독립적인 특징을 가지 고 있다.

각 모음을 구분하는 특징에는 여러 가지 요소가 있는데, 대 표적으로 기본주파수(fundamental frequency) 또는 포먼트 (formant)와 같은 주파수 특성을 들 수 있다. Gelfer \& Bennett(2013)는 성별에 따라 동일한 모음의 발성에 사용되는 기본
주파수가 다르므로 기본주파수가 성별을 인식하는 데 중요한 역할을 한다고 보고하였다. 한국어의 경우에도 주파수 특성은 모음을 구분하는 중요한 특징으로 보고되고 있다. Choi(2010) 에서는 20 30대의 남성 30명을 대상으로 단모음 5개//아/, /에/, /이/, /오/, /우/)의 F1 (first formant), F2, F3, F4를 측정하였다. 그 결과, $\mathrm{F} 1$ 은 /아/가 평균 $663.0 \mathrm{~Hz}$ 로 제일 높은 포먼트 특성 을 보였고, /이/가 평균 $292.6 \mathrm{~Hz}$ 로 제일 낮은 포먼트 특성은 보였으며, F2에서는 /이/가 2,243.8 Hz로 가장 높은 포먼트 특 성이 보였고, /우/가 $1,335.5 \mathrm{~Hz}$ 로 제일 낮은 포먼트 특성을 보 였다. F3에서는 / 이/가 3,265.3 Hz로 제일 높은 포먼트 특성을 보였고, /에/가 3,080.4 Hz로 제일 낮은 포먼트 특성을 보였으 며, F4는/우/가 5,097.9 Hz로 제일 높은 포먼트 특성을 보였고, /에/가 4,278.1 Hz로 제일 낮은 포먼트 특성을 보였다. Yoon \& $\operatorname{Kim}(2015)$ 은 20 30대 한국 성인 여성 10명의 자연발화 음성 
인 서울코퍼스를 대상으로 포먼트 분석을 통하여 모음의 특성 을 구분하고자 하였다. F1의 경우 / 아/가 $609 \mathrm{~Hz}$ 로 제일 높은 포먼트 특성을 보였고, /오/가 $365 \mathrm{~Hz}$ 로 제일 낮은 포먼트 특 성을 보였으며, $\mathrm{F} 2$ 에서는 /이/가 2,279 Hz로 제일 높은 포먼트 특성을 보였고, /오/가 $1,057 \mathrm{~Hz}$ 로 제일 낮은 포먼트 특성을 보 였다. 또한, 주파수 특성을 이용한 모음의 특성 분석은 언어 간 에도 활발히 이루어지고 있다. Lee et al.(2005)은 한국어 음소 의 주파수 특성을 분석하여 영어의 주파수 특성과 비교한 결 과, 유사한 모음에서 두 언어 간의 주파수 특성이 다름을 확인 하였다. 예를 들어, 한국어 $/ \neg /, / \pi /, / \exists /$ 의 주파수 범위는 $600 \sim 3,300 \mathrm{~Hz}$ 이지만 영어 /g/, /k/의 범위는 1,500 4,000 Hz 로 영어가 더 높은 반면, 한국어 /ㅂ/, /삐, /프/의 주파수 범위는 $1,000 \sim 2,400 \mathrm{~Hz}$ 인데 반해 영어 /b/, /p/의 범위는 500 1,500 $\mathrm{Hz}$ 로 한국어가 더 높았다. 위에서 언급한 내용을 종합하면, 주 파수 특성은 모음을 구분하는 주요한 요소라고 말할 수 있다.

하지만 모음의 길이(duration)도 모음의 특성을 구분하는 요 소가 될 수 있다. 최근 한 연구(Mi et al., 2016)에서는 모국어가 영어인 집단과 중국어인 집단을 대상으로, 모음의 길이에 따른 영어 모음의 인지능력을 측정하였다. 그 결과, 모국어가 영어인 집단에서는 모음 길이를 인위적으로 $170 \mathrm{~ms}$ 이하로 줄였을 때 보다 본래의 모음 길이였을 때 인지 점수가 평균적으로 $5.5 \%$ 높았으며, 모국어가 중국어인 집단에서는 평균적으로 $6.8 \%$ 높 았다. 또한, Chung \& Yoon(2015)은 낭독체가 아닌 인터뷰형식 으로 미국인들의 영어를 녹음한 벅아이코퍼스를 활용하여 성 별, 연령별, 집단별로 나누어서 모음 길이를 분석하였는데, 전 체적인 평균을 보면 /ae/가 $116 \mathrm{~ms}$ 로 가장 길었고, /uh/가 62 $\mathrm{ms}$ 로 가장 짧았다. 이외에도 최근 선행연구(Holt et al., 2015) 에서는 영어 모음 길이를 성별, 인종별, 연령별로 비교하였는데 같은 영어 안에서도 성별, 인종별로 모음 길이에서 차이가 나는 것을 확인할 수 있었다. 성별로 나누었을 때, 여성이 남성보다 모음 길이가 더 길었고, 인종별로 나누었을 때는 흑인이 백인보 다 긴 평균모음길이를 보였다. Holt et al.(2015)은 이렇게 도출 된 시간패턴의 차이가 언어발달 치료법 세팅에 유용한 정보를 제공할 것이라고 보고하였다. 예를 들어, 동일 모음의 발성길이 가 흑인이 백인보다 더 길기 때문에 흑인을 대상으로 언어발달 장애의 정도를 판단할 때, 백인의 기준보다 긴 발성길이의 기준 의 적용이 정확한 진단에 필요하다고 보고하였다.

본 연구의 목적은 한국어의 모음 길이를 측정하여 길이에 따 른 모음의 특성을 분석하고자 하였다. 영어 기반의 모음길이 연 구들은 보고되고 있으나, 한국어의 모음 길이에 대한 보고는 활발하게 이루어지지 않고 있다. 하지만 한국어는 영어와는 여 러 가지 음성학 및 음향학적인 특성이 다르다는 점에서 모음의 길이 또한 차이가 발생할 수 있다. 따라서 본 연구를 통해, 한
국어 각 모음의 길이를 측정하여 성별 및 모음별 특성을 분석 함과 동시에 외국에서 보고된 영어모음의 평균 길이를 한국어 와 비교하여 그 특성을 분석하고자 한다.

\section{MATERIALS AND METHODS}

\section{연구 대상}

본 연구는 건청성인 남녀 각각 10 명씩 총 20명을 대상으로 하 였다. 연구대상자들의 연령분포는 20 21세로 평균 연령은 20.25세였다(남: 20.5 세, 여: 20.0세). 연구대상자들의 주 거주 지역은 강원도 9 명, 서울 7 명, 경기도 3 명, 대전 1명이었으며, 지 역 방언을 쓰는 대상자는 없었다. 또한, 본 연구는 대상자들에 게 단어를 제시하고 녹음해야 하기 때문에 발성에 어려움이 없 는 참여자를 대상으로 연구를 실시하였다. 모든 대상자들은 실 험에 들어가기 앞서 순음청력검사와 고막운동도 검사를 실시하 였다. 순음청력검사는 250 8,000 Hz 대역을 기준으로 실시하 였고 pure-tone average 3 분법 결과 모두 $20 \mathrm{~dB}$ 이내로 정상청 력임을 확인하였다(GSI 61; Grason-Stadler, Eden Prairie, $\mathrm{MN}, \mathrm{USA}$ ). 고막운동도 검사에서도 모든 참가자들의 결과는 $\mathrm{A}$ 타입으로 정상임을 확인하였다. 이외에도 이명, 이충만감 등 이과적 증상을 가진 대상은 없었으며 특정 질환이나 과거력은 없었다. 연구대상은 자율적으로 참여 의사를 밝혔으며 실험에 들어가기 앞서서 연구자는 연구의 목적 및 방법 등 충분한 설 명을 제공하였다. 또한 데이터 수집에 앞서 임상실험윤리위원 회(Institute Review Board, IRB)의 승인을 받았으며(승인번호: HIRB-2016-006), 실험 참여 후에는 참여에 대한 적절한 보수 를 지급하였다.

\section{연구 절차}

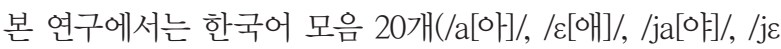
[애]/, /ə[어]/, /e[에]/, /jə[여]/, /je[예]/, /o[오]/, /wa[와]/, /wE [왜]/, /we[외]/, /jo[요]/, /u[우]/, /wə[워]/, /wi[위]/, /ju[유]/, /i $[$ 으 $] /, / \mathrm{iy}[$ 의 $] /, / \mathrm{i}[$ 이]/)의 모음 길이를 측정하기 위하여 $/ \mathrm{h}(\mathrm{V})$ $\mathrm{da} /$ 형식을 적용하여 녹음하였다. 한국어 모음은 총 21개이지 만 국제음성기호(international phonetic alphabet, IPA)에서 /we[웨]/와 / we[외]/의 경우, 같은 음성기호를 사용하기 때문에

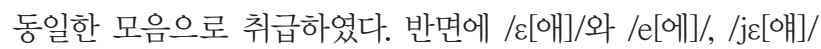
와 /je[예]/, /wE[왜]/와 / we[외]/는 거의 동일한 발음으로 발성되 지만 국제음성기호(IPA)에서 다른 발음으로 구분하여 사용하 고 있기 때문에 따로 나누어 녹음을 진행하였다. 본 연구는 어 형변화의 대표형인 $/ \mathrm{h}(\mathrm{V}) \mathrm{d} /$ 형식에서 모음 길이를 측정한 선행 연구들과 유사한 방법을 사용하여 모음의 길이를 측정하였다 (Holt et al., 2015; Yang, 1996). 영어 모음 분석에서 $/ \mathrm{h}(\mathrm{V}) \mathrm{d} /$ 형 
식이 많이 쓰이는 이유는 $/ \mathrm{h} /$ 가 무성변이음이어서 자음 앞의 동시조음 효과를 받지 않고, 치경음 /d/ 또한 상대적으로 전방 모음 포먼트의 영향을 적게 받기 때문이다(Yang, 1996). 또한, $/ \mathrm{h}(\mathrm{V}) \mathrm{d} /$ 형식을 쓰는 이유 중의 하나는 자발화 음성에서 통제 하기 어려운 자음적인 환경이나 운율 패턴으로부터 영향을 적 게 받기 때문이다(Holt et al., 2015). 하지만 한국어 모음의 특 성상, 본 연구에서는 $/ \mathrm{h}(\mathrm{V}) \mathrm{d} /$ 형식보다 $/ \mathrm{h}(\mathrm{V}) \mathrm{da} /$ 형식으로 녹음 을 하는 것이 자연스러운 발성을 유도한다는 선행연구(Yang, 1996)의 결과에 기반하여 모음의 녹음을 진행하였다. 따라서 모음을 $/ \mathrm{h}(\mathrm{V}) \mathrm{da} /$ 에 적용하여 /하다/, /해다/, /햐다/, /해다/, /허 다/, /헤다/, /혀다/, /혜다/, /호다/, /화다/, /홰다/, /회다/, /효다/, /후다/, /훠다/, /휘다/, /휴다/, /흐다/, /희다/, /히다/로 발음하게 하였고, 그 중에서 /a/, /ع/, /ja/, /je/, /ə/, /e/, /jə/, /je/, /o/, /wa/, /we/, /we/, /jo/, /u/, /wə/, /wi/, /ju/, /ì/, /iyy/, /i/ 의 모음 길이만 을 추출하여 분석하였다. 모음은 Praat v6.0.19(Boersma \& Weenink, 2016)를 사용하여 추출하였다. 모음의 추출기준은 선 행논문(Holt et al., 2015)의 기준과 동일한 방식을 따랐는데, 성 문마찰음인 /h/의 산출 이후에 발성이 시작되는 지점을 모음의 발성 시작점으로 하고, /da/를 산출하기 전에 모음의 진폭이 떨 어지는 지점을 종료 지점으로 하여 모음의 길이를 측정하였다.

연구는 한림대학교 청각학실습실 내의 방음실에서 이루어졌 으며, 녹음장비는 음성분석프로그램(computerized speech lab, CSL, KayPENTAX ${ }^{\mathrm{TM}}$, Montvale, NJ, USA) 및 마이크(Sennheiser e-835s, Wedemark, Germany)를 사용하였다. 녹음 시 샘 플링모드는 44,100 Hz로 설정하였고 양자화는 16 bits로 설정 하였다. 주어진 단어를 녹음하기 전에 대상자의 긴장을 풀어주 기 위해 연습세션을 진행하였고 편안히 의자에 앉은 상태로 마 이크로부터 입이 $10 \mathrm{~cm}$ 떨어진 거리에서 녹음하게 하였다. 한 모음당 3 4 sec 간격으로 5 회를 연속적으로 발음하게 하였으 며 일정한 성량으로 발음하게 하였다. 녹음과정에서 발음이 부 적합하다고 판단되는 경우에는 재녹음을 실시하였으며 녹음
된 5 회의 발음 중 첫 발음과 마지막 발음을 제외한 3 회의 발음 만을 분석에서 사용하였다.

\section{통계 분석}

녹음된 평균 모음 길이 데이터를 가지고 성별 및 모음에 따 른 길이를 비교하고자 하였다. 자료분석은 SPSS-22(IBM SPSS Inc., Armonk, NY, USA) 소프트웨어를 이용하여 진행하였고 반복측정된 이원분산분석(two-way repeated measures ANO$\mathrm{VA})$ 을 이용하여 성별 및 모음에 따른 분석을 실시하였다. 모든 통계분석의 유의수준은 0.05 미만이었고, 사후검정은 Bonferroni test를 통하여 분석하였다.

\section{RESULTS}

성별 및 모음에 따른 모음 길이의 통계결과는 다음과 같다 (Table 1). 성별에 따른 모음의 길이는 통계적으로 유의미하였으 며 $[\mathrm{F}(1,1160)=345.664, p<0.001]$, 모음 간에서도 모음의 길이 는 유의미한 것으로 나타났다[F(19, 1160) $=9.716, p<0.001]$. 또 한, 모음의 평균길이가 긴 모음일수록 남녀 간 모음 길이의 차이 가 더 증가하는 것으로 나타났다[F(19, 1160) $=2.100, p<0.05]$.

Table 1. Results of two-way repeated measures ANOVA between gender and vowels for vowel durations

\begin{tabular}{lll}
\hline Measurements & \multicolumn{1}{c}{ F values } & $p$ values \\
\hline Gender & $\mathrm{F}(1,1160)=345.664$ & $p<0.001$ \\
Vowels & $\mathrm{F}(19,1160)=9.716$ & $p<0.001$ \\
Vowels $\times$ Gender & $\mathrm{F}(19,1160)=2.100$ & $p<0.05$ \\
\hline
\end{tabular}

Table 2. Means and SDs for vowel duration in milliseconds for male and female speakers

\begin{tabular}{lcc}
\hline & M & SD \\
\hline Male & 79.45 & 20.85 \\
Female & 113.77 & 43.90 \\
\hline
\end{tabular}

M: mean, SD: standard deviation

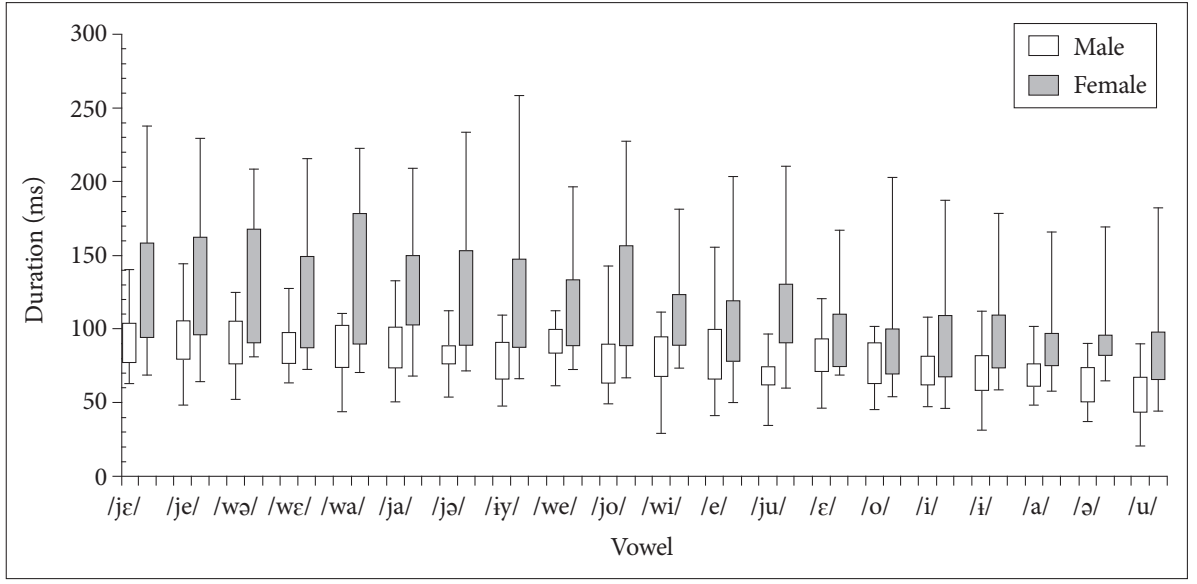

Figure 1. A box plot of vowel durations in milliseconds for Korean male and female speakers. 
Table 2와 Figure 1은 성별에 따른 한국어 평균 모음 길이를 보여주고 있다. 여성의 모음 평균 길이는 $113.77 \mathrm{~ms}$ [standard deviation (SD): \pm 43.90]였고 남성의 모음 평균 길이는 $79.45 \mathrm{~ms}$ (SD: \pm 20.85 로 한국어 모음 길이는 평균적으로 여성이 남성 보다 약 $34.32 \mathrm{~ms}$ 더 긴 것으로 확인되었다 $(p<0.001)$. Figure 1 에서 제시하듯이 각 모음별로도 여성이 남성보다 상대적으로 긴 모음 길이를 가지고 있었다. 예를 들어, /ju/의 경우 여성의 평균 모음 길이는 남성보다 $50.87 \mathrm{~ms}$ 더 길었으며(남성 평균: $67.03 \mathrm{~ms}$, 여성 평균 : $117.90 \mathrm{~ms}$ ), / $/$ /는 여성이 남성보다 평균 적으로 $16.27 \mathrm{~ms}$ 더 긴 것을 확인할 수 있었다(남성 평균: 81.60 $\mathrm{ms}$, 여성 평균 : $97.87 \mathrm{~ms})$.

Table 3, Figure 1에서는 각 모음의 평균 길이를 나타내고 있 다. 남성의 경우, 가장 긴 모음은 /jع/(92.63 ms)였고 가장 짧은 모음은 $/ \mathrm{u} /(56.53 \mathrm{~ms})$ 였다. 남성의 경우, 모음 길이를 $10 \mathrm{~ms}$ 단 위로 구분하였을 때, $90 \mathrm{~ms}$ 이상 5 개 모음, $89.9 \mathrm{~ms}$ 이하 $80 \mathrm{~ms}$ 이상 5 개 모음, $79.9 \mathrm{~ms}$ 이하 $70 \mathrm{~ms}$ 이상 6 개 모음, $69.9 \mathrm{~ms}$ 이 하 $60 \mathrm{~ms}$ 이상 3 개 모음, $60 \mathrm{~ms}$ 이하는 1개 모음으로 나타났 다. 여성의 경우, 가장 긴 모음은 /jع/(132.37 ms)였고 가장 짧은 모음은 $/ \mathrm{u} /(88.73 \mathrm{~ms})$ 였다. 모음 길이를 $10 \mathrm{~ms}$ 단위로 구분 하 였을 때, $130 \mathrm{~ms}$ 이상 6개 모음, $129.9 \mathrm{~ms}$ 이하 $120 \mathrm{~ms}$ 이상 3개 모음, $119.9 \mathrm{~ms}$ 이하 $110 \mathrm{~ms}$ 이상 3개 모음, $109.9 \mathrm{~ms}$ 이하 100

Table 3. Means and SDs for Korean vowel durations in milliseconds for male and female speakers

\begin{tabular}{|c|c|c|c|c|}
\hline & \multicolumn{2}{|c|}{ Male } & \multicolumn{2}{|c|}{ Female } \\
\hline & $\mathrm{M}$ & SD & $\mathrm{M}$ & SD \\
\hline$/ \mathrm{j} \varepsilon /^{*}$ & 92.63 & 20.27 & 132.37 & 48.73 \\
\hline$/ \mathrm{je} / *$ & 91.77 & 22.47 & 132.27 & 48.28 \\
\hline /wo/* & 91.07 & 18.95 & 131.43 & 44.02 \\
\hline$|\mathrm{w} \varepsilon|^{*}$ & 90.47 & 15.63 & 130.63 & 44.98 \\
\hline$/ \mathrm{wa} /{ }^{*}$ & 84.67 & 20.11 & 133.37 & 49.09 \\
\hline$/ \mathrm{ja} /{ }^{*}$ & 87.97 & 20.31 & 127.00 & 38.16 \\
\hline$/ \mathrm{j} \partial /^{*}$ & 81.57 & 12.95 & 127.57 & 50.30 \\
\hline /iy/* & 77.03 & 16.48 & 130.77 & 55.84 \\
\hline /we/ & 90.13 & 13.13 & 116.10 & 36.20 \\
\hline$/ \mathrm{jo} / *$ & 79.60 & 22.09 & 125.40 & 49.39 \\
\hline /wi/* & 78.53 & 20.47 & 114.07 & 34.11 \\
\hline /e/ & 87.23 & 31.65 & 104.30 & 42.32 \\
\hline$/ \mathrm{ju} / *$ & 67.03 & 13.42 & 117.90 & 4.061 \\
\hline$|\varepsilon|$ & 81.60 & 17.06 & 97.87 & 31.26 \\
\hline /o/ & 76.20 & 16.94 & 94.40 & 36.94 \\
\hline /i/ & 71.43 & 14.12 & 93.43 & 37.53 \\
\hline /it/ & 70.23 & 18.14 & 94.00 & 30.90 \\
\hline $\mid \mathrm{a} /$ & 69.90 & 14.15 & 90.37 & 26.65 \\
\hline /o/ & 63.47 & 15.36 & 93.40 & 25.85 \\
\hline$/ \mathrm{u} /$ & 56.53 & 16.59 & 88.73 & 37.53 \\
\hline
\end{tabular}

${ }^{*} p<0.05$. M: mean, SD: standard deviation $\mathrm{ms}$ 이상 1 개 모음, $99.9 \mathrm{~ms}$ 이하 $90 \mathrm{~ms}$ 이상 6 개 모음, $89.9 \mathrm{~ms}$ 이하는 1개 모음으로 나타났다.

모음의 길이는 평균적으로 이중모음(diphthong)이 단모음 (monophthong)보다 긴 것으로 측정되었다. 남성의 경우, 단모 음인 /o/, /i/, /i/, /a/, /ə/, /u/의 모음 길이는 각각 76.2, 71.4, 70.2, 69.9, 67.0, $63.5 \mathrm{~ms}$ 로 모두 $77 \mathrm{~ms}$ 미만이었지만 이중모음 인 /je/, /je/, /wə/, /we/, /we/, /ja/는 각각 92.6, 91.8, 91.1, 90.5, 90.1, $88.0 \mathrm{~ms}$ 로 모두 $87 \mathrm{~ms}$ 이상으로 측정되었다. 마찬가지로 여성의 경우, 단모음인 /o/, /i/, /i/, / / //, /a/, / / / 의 모음 길이는 각각 94.4, 94.0, 93.4, 93.4, 90.4, $88.7 \mathrm{~ms}$ 로 모두 $95 \mathrm{~ms}$ 미만이 었지만 이중모음인 /wa/, /je/, /je/, /wə/, / /yy/, /we/는 각각 133.4, 132.4, 132.3, 131.4, 130.8, $130.6 \mathrm{~ms}$ 로 모두 $130 \mathrm{~ms}$ 이상으로 측정되었다.

\section{DISCUSSIONS}

본 연구의 결과에서 여성의 모음 길이는 남성의 모음 길이보다 평균적으로 $34.32 \mathrm{~ms}$ 정도 긴 것으로 확인되었다 $(p<0.001)$. 이는 성별에 따른 영어의 모음 길이를 비교한 선행연구(Holt et al., 2015)와 유사한 결과였다. Holt et al.(2015)는 영어모음의 평균 길이 차이가 여성이 남성보다 약 $25.6 \mathrm{~ms}$ 더 길다고 보고 하였다. 그러나 Bonferroni 사후분석 결과, 성별에 따른 모든 한국어 모음의 길이가 유의미하게 차이나는 것은 아니었다. 총 20 개의 모음 중, 11 개의 모음(/je/, /je/, /wə/, /we/, /wa/, /ja/, /jə/, /iy/, /jo/, /wi/, /ju/)에서는 성별에 따라 유의미한 차이가 나타났지만, 나머지 9개의 모음에서는 성별에 따른 모음 길이 의 차이가 유의미하지 않는 것으로 분석되었다(Table 3). 특히 이중모음에서는 성별 간 유의미한 길이 차이가 뚜렷했지만 단모 음에서는 유의미한 차이가 거의 나타나지 않았다. 이는 이중모 음이 가지고 있는 구조적 특징이 반영된 결과라고 생각된다. 이 중모음은 활음과 단모음이 결합되어 있는 형태이기 때문에 이중 모음을 구성하는 각 모음의 길이 특성이 반영된다(Kim, 2001). 본 연구에서 평균 단모음의 길이는 성별에 따른 유의미한 길이 차이가 나타나진 않았지만, 여성의 평균 단모음 길이는 남성의 평균 단모음 길이보다 길었다. 이러한 정량적인 각 단모음의 길 이 차이가 이중모음에서 더욱 두드러진 남녀 간 길이 차이를 보 였고, 그 차이는 통계적으로 유의미한 차이를 나타낼 정도로 영 향을 준 것으로 해석할 수 있다.

그러나 모음의 길이는 선행하는 자음 및 후행하는 자음의 특성에 따라서도 달라질 수 있고, 동일한 모음이라 할지라도 어 말과 어미에서 측정되는 모음의 길이는 달라질 수 있으며, 이러 한 길이의 차이는 개인마다 가지고 있는 발성 및 발화 특징에 따라 달라질 수 있기 때문에(Umeda, 1975), 본 연구의 결과가 
동일한 문장을 낭독 시, 남성이 여성보다 항상 발화속도가 더 빠르다고 가정할 수는 없다고 본다. Holt et al.(2015)도 영어 모 음의 평균 길이가 여성이 남성보다 길다 할지라도 일반적인 대 화의 평균 발화속도는 관여하는 다른 여러 요소(자음, 개인별 기본 발화 속도, 구강 구조 등) 등에 의하여 달라질 수 있다고 언급하였다. 따라서 본 연구의 결과는 동시조음효과와 전방 모 음포먼트의 영향을 억제하여 해당 모음의 길이를 측정한 기준 에서 $50 \%$ (20개 중 11 개 모음) 정도의 모음에서 여성이 남성보 다 긴 발성시간을 보인 것으로 해석할 수 있다.

Table 4, 5에서는 남녀 각각의 모음 간 길이에 따른 사후분석 결과를 보여주고 있다. 모음 간의 모음 길이는 전체적으로 유의 미한 차이를 보였지만 $(p<0.001)$, Bonferroni 사후분석 결과 일부 모음들 간에는 유의미한 길이차이를 보이지 않는 것으로 나타났다. Table 4, 5에서 모음 간에 유의미한 길이 차이를 가진 모음의 경우에는 음영을 짙게 표시하였고, 유의미한 길이 차이 가 없는 경우에는 음영처리를 하지 않았다. 예를 들어, 남자의 경우(Table 4), /je/는 /i/, /il, /a/, /ju/, /ə/, /u/와 유의미한 길이 차이를 보인 반면, 빈칸으로 되어 있는 /je/부터 /o/까지는 /je/ 와 유의미한 길이 차이가 발견되지 않았다. 여자의 경우(Table $5), / \mathrm{wa} /$ 는 /i/, /i/, /ə/, /a/, /u/와 유의미한 길이 차이를 보인 반 면, /je/부터 /o/까지 14 개의 모음들은 / wa/와 유의미한 길이 차 이를 보이지 않았다.

본 연구에서 측정된 한국어 모음의 길이는 영어 모음의 평균
길이와 비교하기 위하여 영어 모음의 길이를 측정한 Holt et al. (2015)와 동일한 기준으로 모음의 길이를 측정하였다. 그 중 국 제음성기호(IPA)가 동일한 대표적인 5개 모음을 선정하여 남녀 를 나누어 평균 모음의 길이를 비교해 보았다(Table 6). 성인 남 성의 한국어 /a/, /e/, /i/, /o/, /u/ 평균 모음 길이는 69.9, 87.2, $71.4,76.2,56.5 \mathrm{~ms}$ 로 전체 평균 모음 길이가 $72.2 \mathrm{~ms}$ 임을 확인 할 수 있었다. 영어의 경우, 남성 평균 모음 길이는 각각 264.6, 258.2, 244.2, 275.5, $245.6 \mathrm{~ms}$ 로 전체 평균 모음 길이가 257.6 $\mathrm{ms}$ 임을 확인하였다. 따라서 남성의 경우, 5 개 대표 영어 모음의 평균 길이는 한국어 모음의 평균 길이보다 약 $185.4 \mathrm{~ms}$ 정도 긴 것으로 나타났다. 한국어의 경우, 여성의 $/ \mathrm{a} /, \mathrm{e} /, \mathrm{i} /, \mathrm{l} / \mathrm{/} / \mathrm{u} /$ 의 평균 모음 길이는 90.4, 104.3, 94.0, 94.4, $88.7 \mathrm{~ms}$ 로 평균 94.4 $\mathrm{ms}$ 였고, 영어의 경우 297.2, 304.3, 284.0, 305.5, $260.3 \mathrm{~ms}$ 로 평 균이 $290.26 \mathrm{~ms}$ 였다. 마찬가지로, 여성의 경우에도 5 개 대표 모 음의 길이는 영어 모음이 한국어 모음보다 평균적으로 195.86 $\mathrm{ms}$ 정도 긴 것을 확인할 수 있었다. 또한, 한국어와 영어는 평 균모음길이에 따른 순서에서도 차이가 나타났다. 한국어의 경 우, 남녀 모두 /e/, /o/, / i/, /a/, / / / 순서로 평균길이가 길었지만 영어의 경우 남성은 $/ \mathrm{o} /, \mathrm{a} / \mathrm{a}, \mathrm{e} / \mathrm{e}, \mathrm{lu} / \mathrm{l} / \mathrm{i} /$ 순으로 모음 길이가 길 었으며 여성은 $/ \mathrm{o} /, \mathrm{el} / \mathrm{la} / \mathrm{l} / \mathrm{i} /, \mathrm{lu} /$ 순이었다. 한국어는 /e/가 남 녀 각각 $87.2,104.3 \mathrm{~ms}$ 로 가장 길었고, $/ \mathrm{u} /$ 가 $56.5,88.7 \mathrm{~ms}$ 로 가장 짧았다. 영어는 남성의 경우 $/ \mathrm{o} /$ 가 $275.5 \mathrm{~ms}$ 로 평균 길이 가 가장 길었고 $/ \mathrm{i} /$ 가 $244.2 \mathrm{~ms}$ 로 가장 짧았으며, 여성은 /o/가

Table 4. Bonferroni post-hoc analysis of 20 vowel durations for Korean male speakers

\begin{tabular}{|c|c|c|c|c|c|c|c|c|c|c|c|c|c|c|c|c|c|c|c|c|c|}
\hline & $\mathrm{j} \varepsilon$ & je & wə & we & we & ja & e & wa & $\varepsilon$ & jə & jo & wi & iy & o & $\mathrm{i}$ & $\dot{\mathbf{i}}$ & a & ju & $\partial$ & $\mathrm{u}$ & $\begin{array}{l}\text { Duration } \\
\text { time }(\mathrm{ms})\end{array}$ \\
\hline $\mathrm{j} \varepsilon$ & & & & & & & & & & & & & & & & & & & & & 92.6 \\
\hline je & & & & & & & & & & & & & & & & & & & & & 91.8 \\
\hline wə & & & & & & & & & & & & & & & & & & & & & 91.1 \\
\hline we & & & & & & & & & & & & & & & & & & & & & 90.5 \\
\hline we & & & & & & & & & & & & & & & & & & & & & 90.1 \\
\hline ja & & & & & & & & & & & & & & & & & & & & & 88.0 \\
\hline $\mathrm{e}$ & & & & & & & & & & & & & & & & & & & & & 87.2 \\
\hline wa & & & & & & & & & & & & & & & & & & & & & 84.7 \\
\hline$\varepsilon$ & & & & & & & & & & & & & & & & & & & & & 81.6 \\
\hline jə & & & & & & & & & & & & & & & & & & & & & 81.6 \\
\hline jo & & & & & & & & & & & & & & & & & & & & & 79.6 \\
\hline wi & & & & & & & & & & & & & & & & & & & & & 78.5 \\
\hline iy & & & & & & & & & & & & & & & & & & & & & 77.0 \\
\hline o & & & & & & & & & & & & & & & & & & & & & 76.2 \\
\hline $\mathrm{i}$ & & & & & & & & & & & & & & & & & & & & & 71.4 \\
\hline$\dot{\mathrm{i}}$ & & & & & & & & & & & & & & & & & & & & & 70.2 \\
\hline $\mathrm{a}$ & & & & & & & & & & & & & & & & & & & & & 69.9 \\
\hline ju & & & & & & & & & & & & & & & & & & & & & 67.0 \\
\hline$\partial$ & & & & & & & & & & & & & & & & & & & & & 63.5 \\
\hline $\mathrm{u}$ & & & & & & & & & & & & & & & & & & & & & 56.5 \\
\hline
\end{tabular}


Table 5. Bonferroni post-hoc analysis of 20 vowel durations for Korean female speakers

\begin{tabular}{|c|c|c|c|c|c|c|c|c|c|c|c|c|c|c|c|c|c|c|c|c|c|}
\hline & wa & $\mathrm{j} \varepsilon$ & je & wə & iy & $\mathrm{w} \varepsilon$ & jə & ja & jo & $\mathrm{ju}$ & we & wi & $\mathrm{e}$ & $\varepsilon$ & o & $\dot{\mathrm{t}}$ & $\mathrm{i}$ & $\partial$ & $a$ & $\mathrm{u}$ & $\begin{array}{l}\text { Duration } \\
\text { time (ms) }\end{array}$ \\
\hline wa & & & & & & & & & & & & & & & & & & & & & 133.4 \\
\hline $\mathrm{j} \varepsilon$ & & & & & & & & & & & & & & & & & & & & & 132.4 \\
\hline je & & & & & & & & & & & & & & & & & & & & & 132.3 \\
\hline wə & & & & & & & & & & & & & & & & & & & & & 131.4 \\
\hline iy & & & & & & & & & & & & & & & & & & & & & 130.8 \\
\hline we & & & & & & & & & & & & & & & & & & & & & 130.6 \\
\hline jə & & & & & & & & & & & & & & & & & & & & & 127.6 \\
\hline ja & & & & & & & & & & & & & & & & & & & & & 127.0 \\
\hline jo & & & & & & & & & & & & & & & & & & & & & 125.4 \\
\hline $\mathrm{ju}$ & & & & & & & & & & & & & & & & & & & & & 117.9 \\
\hline we & & & & & & & & & & & & & & & & & & & & & 116.1 \\
\hline wi & & & & & & & & & & & & & & & & & & & & & 114.1 \\
\hline e & & & & & & & & & & & & & & & & & & & & & 104.3 \\
\hline$\varepsilon$ & & & & & & & & & & & & & & & & & & & & & 97.9 \\
\hline o & & & & & & & & & & & & & & & & & & & & & 94.4 \\
\hline$\dot{i}$ & & & & & & & & & & & & & & & & & & & & & 94.0 \\
\hline $\mathrm{i}$ & & & & & & & & & & & & & & & & & & & & & 93.4 \\
\hline$\partial$ & & & & & & & & & & & & & & & & & & & & & 93.4 \\
\hline$a$ & & & & & & & & & & & & & & & & & & & & & 90.4 \\
\hline $\mathrm{u}$ & & & & & & & & & & & & & & & & & & & & & 88.7 \\
\hline
\end{tabular}

Table 6. Average vowel durations in milliseconds for Korean and English male and female speakers

\begin{tabular}{ccccccc}
\hline \multirow{2}{*}{ Vowel } & \multicolumn{3}{c}{ Male } & & \multicolumn{2}{c}{ Female } \\
\cline { 2 - 3 } \cline { 5 - 6 } & Korean & English & & Korean & English \\
\hline /a/ & 69.9 & 264.6 & & 90.4 & 297.2 \\
/e/ & 87.2 & 258.2 & & 104.3 & 304.3 \\
/i/ & 71.4 & 244.2 & & 94.0 & 284.0 \\
/o/ & 76.2 & 275.5 & & 94.4 & 305.5 \\
/u/ & 56.5 & 245.6 & & 88.7 & 260.3 \\
\hline
\end{tabular}

$305.5 \mathrm{~ms}$ 로 가장 길고 $/ \mathrm{u} /$ 가 $260.3 \mathrm{~ms}$ 로 가장 짧은 평균 길이 를 나타내었다.

이러한 차이가 나는 이유는 여러 음성학 및 언어학적인 이유 가 있을 수 있지만 대표적으로 음절구조(syllable structure)의 차이를 이유로 들 수 있다. 한국어는 $/ \mathrm{h}(\mathrm{V}) \mathrm{da} /$ 구조가 2음절로 나뉘지만 영어의 경우에는 $/ \mathrm{h}(\mathrm{V}) \mathrm{d} /$ 구조가 1 음절로 발음된다. Yang et al.(1991)은 영어 모음이 한국어 모음에 비해 평균적으 로 긴 길이를 가지는 이유가 이러한 음절구조의 차이 때문이라 고 예측하였다. 아마도 본 연구에서 2음절로 발음되는 한국어 보다 1음절로 발음되는 영어의 경우에, 더 빠른 온셋(onset)과 늦은 오프셋(offset)으로 모음길이가 측정될 수 있기 때문에 평 균적으로 더 긴 모음길이를 보이는 것으로 생각된다. 또는 영어 의 강세(accent)특징이 두 언어 간 모음의 길이 차이에 반영되 었을 수 있다. 영어 낱말에서 강세가 동반되는 모음은 강세가 동반되지 않는 모음에 비해 더 강하고, 높고, 길게 발음되는 특
징이 있다(Prator \& Robinett, 1985). 이와 같이 강세박자언어 (stress-timed language)인 영어와 달리 한국어는 낱말 단위로 뚜렷이 구분되는 강세 차이가 없어 음절박자언어(syllabletimed language)로 구분할 수 있다. 따라서 $/ \mathrm{h}(\mathrm{V}) \mathrm{da} /$ 형태로 모 음을 녹음할 때, 영어 /(V)/는 강세로 발음되는 반면, 한국어의 $/(\mathrm{V}) /$ 는 영어에 비해 약한 강도로 발성되는 강세 특성이 남녀 모두에서 한국어의 평균모음의 길이가 영어에 비해 짧은 이유 중 하나라고 생각된다.

본 연구는 독립발화조건 $(/ \mathrm{h}(\mathrm{V}) \mathrm{da} /)$ 에서 모음의 길이를 측정 함으로써 자발화 상황에서 통제하기 어려운 선행 및 후행 자음 의 간섭 및 운율적 패턴에 영향을 받지 않고 모음 고유의 길이 를 측정하여 성별 및 모음 간의 길이 차이를 분석하였다(Holt et al., 2015; Yang, 1996). 본 연구가 모음 고유의 길이를 측정 한 점과 영어 모음을 녹음하여 길이를 분석한 선행연구(Holt et al., 2015)와 동일한 녹음 및 분석방법을 사용하여 직접적인 비 교가 가능했던 것은 본 연구가 가지는 의의라고 할 수 있다. 하 지만 언어재활세팅에서 이러한 특성을 적용하여 실질적으로 모 음 길이 특성을 재활에 활용하기 위해서는 실제 발성 환경인 자 발화 또는 연속발화 상황에서의 길이측정 연구가 후속연구로 진행되어야 한다고 생각한다.

본 연구는 한국어 모음 20 개의 길이를 측정하여 성별, 모음 별로 구분하여 비교하였고, 동일한 모음 길이 측정법을 사용하 여 길이를 측정한 영어 모음 중 유사한 국제발음기호를 가진 대 
표 모음들과 평균 모음 길이를 비교하였다. 그 결과, 일부 모음 들은 성별에 따라 유의미한 길이의 차이를 보였고, 모음 간에도 유의미한 길이 차이가 존재함을 확인하였다. 또한 평균적으로 영어 모음의 길이가 한국어의 모음 길이보다 긴 것을 확인할 수 있었다. 본 연구의 결과는 한국어 모음의 길이에 대한 유용 한 정보를 제공하고 있으며, 모음의 길이 특성은 각 모음을 구 분하는 여러가지 특성 중의 하나의 요소가 될 수 있을 것이라 생각된다.

중심 단어 : 음향학적 특성·모음·길이.

\section{Acknowledgments}

이 성과는 2015년도 정부(미래창조과학부)의 재원으로 한국연구 재단의 지원을 받아 수행된 연구임(NRF-2015R1C1A1A01052458).

\section{REFERENCES}

Boersma, P. \& Weenink, D. (2016). Praat: Doing phonetics by computer [Computer program]. Version 6.0.19. Retrieved from http://www. praat.org/

Choi, Y. L. (2010). Fundamental acoustic investigation of Korean male 5 monophthongs. The Journal of the Korea Contents Association, 10(6), 373-377.

Chung, H. J. \& Yoon, K. C. (2015). A study on the vowel duration of the buckeye corpus. Journal of the Korean Society of Speech Sciences, 7(4), 103-110.

Gelfer, M. P. \& Bennett, Q. E. (2013). Speaking fundamental frequency and vowel formant frequencies: effects on perception of gender. Journal of Voice: Official Journal of the Voice Foundation, 27(5), 556-566.

Holt, Y. F., Jacewicz, E., \& Fox, R. A. (2015). Variation in vowel duration among Southern African American English speakers. American Journal of Speech-Language Pathology, 24(3), 460-469.

Kim, M. S. (2001). A study on the traits of Korean dipthong '-f' by means of formants analysis. The Korean Language and Literature, 72, 1-15.

Lee, J. H., Jang, H. S., \& Jung, H. J. (2005). A study on frequency characteristics of Korean phonemes. Audiology, 1(1), 59-66.

Mi, L., Tao, S., Wang, W., Dong, Q., Guan, J., \& Liu, C. (2016). English vowel identification and vowel formant discrimination by native Mandarin Chinese- and native English-speaking listeners: The effect of vowel duration dependence. Hearing Research, 33, 58-65.

National Institute of Korean Language. (2016). Standard Korean Language Dictionary. Seoul: Doosan Donga.

Prator, C. \& Robinett, B. (1985). Manual of American English pronunciation (4th ed.). New York: Holt, Rinehart, and Winston.

Umeda, N. (1975). Vowel duration in American English. The Journal of the Acoustical Society of America, 58(2), 434-445.

Yang, B. (1996). A comparative study of American English and Korean vowels produced by male and female speakers. Journal of Phonetics, 24(2), 245-261.

Yoon, K. \& Kim, S. (2015). A comparative study on the male and female vowel formants of the Korean corpus of spontaneous speech. Journal of the Korean Society of Speech Sciences, 7(2), 131-138. 